\title{
ANTICORPOS LÍTICOS DETECTADOS EM LÍQUIDO PERICÁRDICO DE CHAGÁSICOS CRÔNICOS
}

\author{
Edison Reis Lopes, Maria Elizabeth Soares Pereira, César Moraes, \\ Antoniana Ursine Krettli e Zigman Brener
}

\begin{abstract}
A pesquisa de anticorpos liticos $(A L)$ através do teste de lise mediada por complemento ( $L M C o$ ) foi positiva em 11 líquidos pericárdicos obtidos de pacientes chagásicos falecidos subitamente ou por causas não relacionadas à doença de Chagas $e$ que estão incluidos em um estudo da forma indeterminada dessa doença. Em todos esses pacientes a sorologia convencional para doença de Chagas apresentou resultados positivos e o quadro anátomo-patológico mostrou lesóes características ou compatíveis com a cardite chagásica crônica. Em 12 líquidos pericárdicos de indivíduos que faleceram por diferentes causas e nos quais a sorologia para doença de Chagas foi negativa, a LMCo também foi negativa. A presença de AL no liquido pericárdico constitui forte evidência da presença de infeç̧ão ativa por $\mathrm{T}$. cruzi nos chagásicos necropsiados e abre perspectivas para o estudo e o melhor conhecimento da patologia da doença de Chagas.
\end{abstract}

Palavras chaves: Doença de Chagas. Liquido pericárdico. Anticorpo lítico. Sorologia anti-T. cruzi.

Anticorpos líticos (AL) detectados pelo teste de lise mediada por complemento (LMCo) usando-se tripomastigotas vivos do Trypanosoma cruzi são encontrados no soro da quase totalidade de chagásicos crônicos com infecção ativa ${ }^{5}$. Esses anticorpos são diferentes daqueles envolvidos no diagnóstico pela sorologia convencional (ASC), dependem da presença do parasita e estão associados à resistência do hospedeiro contra o $T$. cruzi. No presente trabalho assinalamos a presença de AL no líquido pericárdico de pacientes chagásicos crônicos falecidos por diferentes causas. Esse achado pode representar um recurso adicional para a demonstração da infecção chagásica ativa em material de necropsias.

\section{MATERIAL E MÉTODOS}

Amostras de líquido pericárdico. O material foi obtido de 23 individuos necropsiados no Departa-

\footnotetext{
Trabalho do Departamento de Patologia, Medicina Legal e Deontologia Médica da Faculdade de Medicina do Triângulo Mineiro, Uberaba; do Centro de Pesquisas René Rachou, FIOCRUZ, Belo Horizonte e do Departamento de Parasitologia da Universidade Federal de Minas Gerais.

Realizado com auxilio financeiro do CNPq (PIDE), FINEP e WHO Special Programme for Research and Training in Tropical Diseases.

Endereço para correspondência: Edison Reis Lopes - Faculdade de Medicina do Triângulo Mineiro, Uberaba - MG. Recebido para publicação em 4/5/84.
}

mento de Patologia, Medicina Legal e Deontologia Medica da Faculdade de Medicina do Triângulo Mineiro (Uberaba, Minas Gerais). Onze eram chagásicos crônicos nos quais o diagnóstico da doença de Chagas foi feito baseado nos achados morfológicos macro e microscópicos do coração ${ }^{39}$; os outros doze, que serviram de controle, pertenciam a individuos não chagásicos falecidos por várias causas.

Dos onze chagásicos, dois tiveram morte violenta e quatro faleceram subitamente devido à tripanossomíase. Nenhum dos seis pacientes apresentava, antes do óbito, ao que se pôde apurar, manifestações clínicas da doença de Chagas. Três faleceram por insuficiência cardiaca em conseqüência da doença e dois por causas não relacionadas à endemia.

Reações sorológicas. Foram realizadas as seguintes reações de sorologia convencional (SC) para o diagnóstico da doença de Chagas: reação de imunofluorescência indireta, reação de fixação do complemento, reação de hemaglutinação indireta, todas feitas com formas de cultivo do parasita ou suas frações. Para esses testes foi empregada metodologia já exposta em trabalho anterior (Lopes e cols 1978) ${ }^{8}$. A reção de ELISA, também utilizada foi realizada de acordo com a técnica original ${ }^{10}$.

Teste de lise mediada por complemento. A pesquisa de anticorpos líticos foi feita de acordo com a técnica descrita por Krettli e cols ${ }^{6}$. Formas sangüineas 
Lopes ER, Pereira MES, Moraes C, Krettli AU, Brener Z. Anticorpos líticos detectados em líquido pericárdico de chagásicos crónicos. Revista da Sociedade Brasileira de Medicina Tropical 17: 127-131, Jul-Set, 1984

tripomastigotas foram obtidas de camundongos irradiados $(650 \mathrm{r})$, infectados com a cepa $Y$ do $T$. cruzi $\mathrm{e}$ sangrados do seio orbital no 7. dia de infecção. $O$ sangue coletado era desfibrinado com o auxílio de pérolas de vidro, diluído com meio de cultivo (TC199 da Difco) e centrifugado a $100 \mathrm{~g}$ por $10 \mathrm{~min}$; o sobrenadante, contendo os tripomastigotas, era centrifugado a $1.000 \mathrm{~g}$ por $15 \mathrm{~min}$ a $4^{\circ} \mathrm{C}$. As formas sangüineas assim obtidas eram lavadas duas vezes em TC1 99 contendo $5 \%$ de soro bovino fetal (TC-SBF) e diluidas para $8 \times 10^{6} / \mathrm{ml}$ com o mesmo meio. Alíquotas de $100 \mu l$ de liquido pericárdico diluído $(1: 2$ a $1: 8)$ eram incubadas com $100 \mu \mathrm{l}$ da suspensão de parasitas por $30 \mathrm{~min}$ a $37^{\circ} \mathrm{C}$; após esse periodo o material era dividido em quatro aliquotas de $50 \mu \mathrm{l}$ em tubos contendo volumes iguais de soro humano não diluido, usado como fonte de complemento (tubo teste), ou soro inativado do mesmo doador (tubo controle). A mistura era incubada por $60 \mathrm{~min}$ a $37^{\circ} \mathrm{C}$ após o que o número de parasitas móveis era determinado em um hemocitômetro e a percentagem de lise calculada. Tubos contendo soro humano normal (controle negativo) ou soro de individuos chagásicos (controle positivo) eram utilizados em cada teste. Todos os testes foram realizados com os líquidos pericárdicos codificados. O cálculo da \% de lise dos tripomastigotas era feito pela seguinte fórmula:

$\%$ lise $=\frac{\text { No parasitas nos tubos controles }- \text { No parasitas nos tubos testes }}{\text { No parasitas nos tubos controles }} \times 100$

Em dois dos 23 casos examinados houve de inicio dificuldades para a realização do teste. Após correção do $\mathrm{pH}$ tornou-se possível a detecção do $\mathrm{AL}$. Não foram incluidos no presente estudo dois casos, um deles cujo óbito decorreu de envenenamento barbitúrico, cujos liquidos pericárdicos lisavam sistematicamente as formas sangüineas, independentemente da adição do complemento à reação.

\section{RESULTADOS}

O teste de LMCo realizado no líquido pericárdico resultou positivo em todos os 11 casos nos quais a sorologia convencional para doença de Chagas havia sido positiva no mesmo material (Tabela 1). As percentagens de lise nas diferentes diluições foram sensivelmente semelhantes às encontradas normalmente com soros de pacientes chagásicos não tratados.

Tabela 1 - Dados gerais de onze chagásicos necropsiados

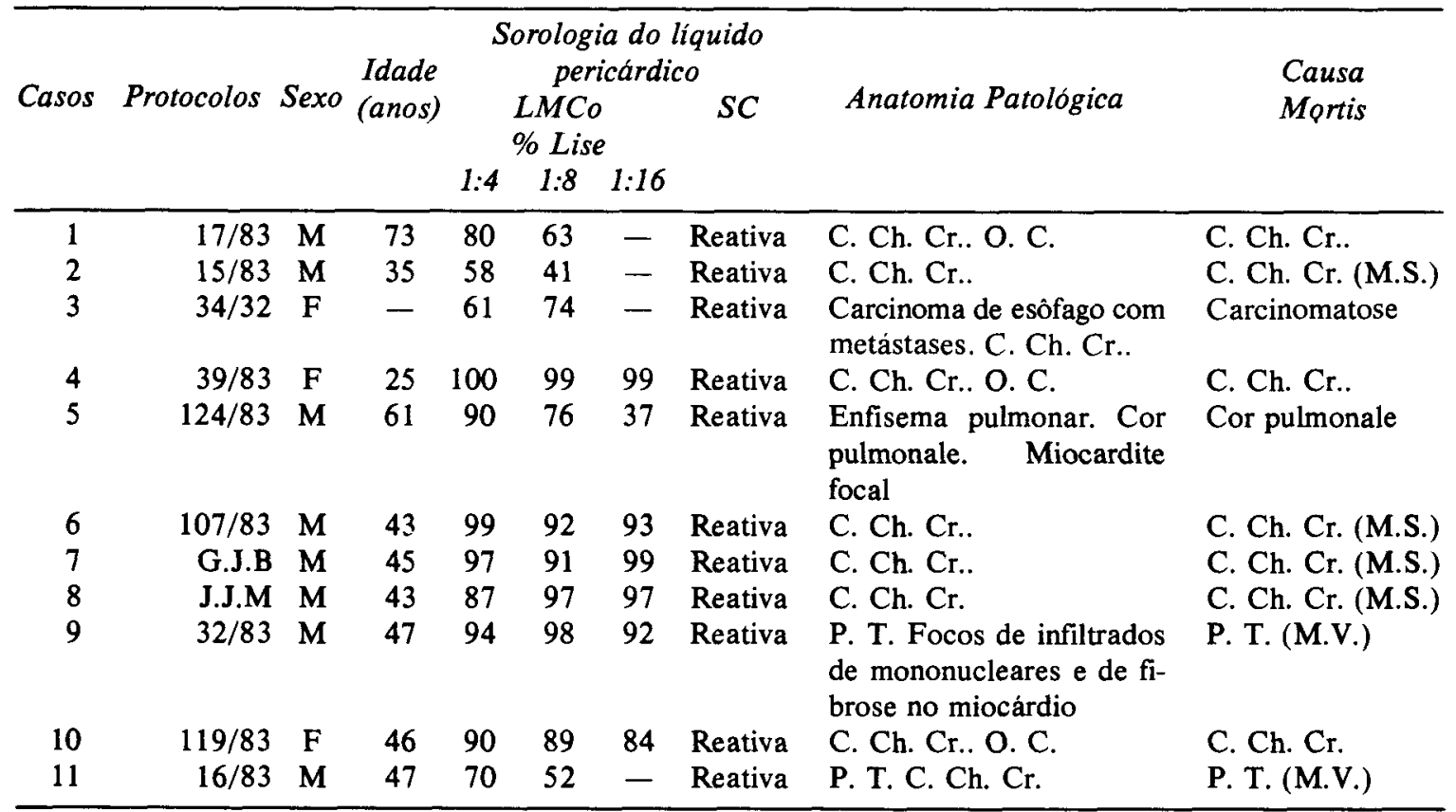

$\mathrm{M}=$ Masculino; $\mathrm{F}=$ Feminino $\mathrm{LMCo}=$ Teste de Lise Mediada por Complemento; $\mathrm{SC}=$ Sorologia Convencional conforme especificado no Material e Metodos; C. Ch. Cr. = Cardite Chagásica Crônica; O. C. = Órgãos Cardíacos; M. S. = Morte súbita; P. T. = Politraumatismo; M. V. = Morte Violenta 
Os resultados da sorologia convencional e da LMCo são compativeis com os achados anátomo-patológicos que, em sua quase totalidade, mostram a existência de lesões caracteristicas ou altamente sugestivas de cardite chagásica crônica, apesar de não se ter observado parasitas em nenhum dos cortes histológicos examinados.

$\mathrm{Na}$ Tabela 2 estão expostos os resultados obtidos com o teste de LMCo nos líquidos peri- cárdicos obtidos de 12 pacientes nos quais a SC para doença de Chagas foi negativa. Nesse grupo pelo menos duas reaçōes sorológicas contra o $T$. cruzi forneceram resultados negativos sendo que em 6 pacientes a doença de Chagas foi excluida pela negatividade de três das quatro reações utilizadas. $\mathrm{Em}$ todos esses líquidos pericárdicos o resultado da LMCo foi negativo. Em nenhum dos 12 casos foram observadas lesōes compativeis ou sugestivas de cardite chagásica.

Tabela 2 - Dados gerais de doze não-chagásicos necropsiados

\begin{tabular}{|c|c|c|c|c|c|c|c|c|c|}
\hline \multirow[t]{2}{*}{ Casos } & \multirow[t]{2}{*}{ Protocolos } & \multirow[t]{2}{*}{ Sexo } & \multirow[t]{2}{*}{$\begin{array}{l}\text { Idade } \\
\text { (anos) }\end{array}$} & \multicolumn{4}{|c|}{$\begin{array}{l}\text { Sorologia do líquido } \\
\text { pericárdico }\end{array}$} & \multirow[t]{2}{*}{ Anatomia Patológica } & \multirow[t]{2}{*}{$\begin{array}{l}\text { Causa } \\
\text { Mortis }\end{array}$} \\
\hline & & & & $1: 4$ & $1: 8$ & $1: 16$ & & & \\
\hline 1 & 3433 & $\mathbf{M}$ & 56 & 0 & 0 & 0 & Negativa & Peritonite pós-gastrectomia & Peritonite \\
\hline 2 & 2283 & $\mathrm{~F}$ & 55 & 5 & 0 & 0 & Negativa & $\begin{array}{l}\text { Hipertensão arterial. } \\
\text { Hemorragia cerebral. }\end{array}$ & A. V. C. \\
\hline 3 & 3434 & $\mathbf{M}$ & 45 & 5 & 0 & 0 & Negativa & $\begin{array}{l}\text { Arteriosclerose. Infarto } \\
\text { cerebral. }\end{array}$ & A. V. C. \\
\hline 4 & $18 / 83$ & $\mathrm{~F}$ & 2 & 0 & 0 & 0 & Negativa & $\begin{array}{l}\text { Broncopneumonite hemor- } \\
\text { rágica }\end{array}$ & Broncopneumonite \\
\hline 5 & 3430 & $\mathbf{M}$ & 67 & 0 & 0 & 0 & Negativa & $\begin{array}{l}\text { Hipertensão arterial. } \\
\text { Broncopneumonite }\end{array}$ & Broncopneumonite \\
\hline 6 & 1083 & $\mathbf{F}$ & 64 & 11 & 5 & 0 & Negativa & T. C. E. & T. C. E. (M.V.) \\
\hline 7 & 3429 & $\mathbf{M}$ & 58 & 19 & 0 & 0 & Negativa & $\begin{array}{l}\text { Hipertensão arterial. } \\
\text { Hemorragia cerebral. }\end{array}$ & A. V. C. \\
\hline 8 & 3431 & $\mathbf{M}$ & 47 & 0 & 0 & 0 & Negativa & Cardiopatia isquêmica & C. I. \\
\hline 9 & $111 / 83$ & $\mathbf{M}$ & 40 & 0 & 0 & 0 & Negativa & Hipertensão arterial. C. H. & C. $\mathrm{H}$. \\
\hline 10 & $31 / 83$ & $\mathbf{M}$ & 48 & 0 & 0 & 0 & Negativa & Pneumonite bilateral & Pneumonite \\
\hline 11 & $25 / 83$ & $\mathbf{M}$ & 35 & 0 & 0 & 0 & Negativa & T. C. E. & T. C. E. (M.V.) \\
\hline 12 & G. S. & $\mathbf{M}$ & 54 & 0 & 0 & 0 & Negativa & Aneurisma aórtico roto & Hemorragia interna \\
\hline
\end{tabular}

$\mathrm{M}=$ Masculino; $\mathrm{F}=$ Feminino; $\mathrm{LMCo}=$ Teste de Lise Mediada por Complemento; $\mathrm{SC}=$ Sorologia Convencional conforme especificado no Material e Métodos; C. Ch. Cr. = Cardite Chagásica Crônica; O. C. = Orgãos Cardiacos; M. S. = Morte súbita; P. T. = Politraumatismo; M. V. = Morte Violenta; A. V. C. = Acidente Vascular Cerebral.

\section{DISCUSSÃO}

Estudos recentes demonstraram a presença, em pacientes chagásicos ${ }^{5}$ ou em animais cronicamente infectados pelo $T$. cruzi ${ }^{4}$, de anticorpos que diferem funcionalmente entre si: a) anticorpos responsáveis pela positividade das reações sorológicas convencionais usadas no diagnóstico da doença de Chagas (ASC); b) anticorpos presentes nos soros de pacientes crônicos com infecção ativa, associados a resistência do hospedeiro ao $T$. cruzi. Apenas essa segunda categoria de anticorpos tem a capacidade de aderir a tripomastigotas vivos do $T$. cruzi, podendo ser detectados através do teste de LMCo, sendo por isso usualmente denominados "anticorpos liticos" (AL), ou pelo teste de imunofluorescência indireta. Os ASC, por sua vez, não aderem aos tripomastigotas vivos mas podem ser detectados através da reação de imunofluorescência com epimastigotas fixados (TIF) ou outras reações sorológicas com antígenos isolados dessas formas. O AL não está presente em animais vacinados com diferentes antígenos de $T$. cruzi $i^{4}$ ou em 
Lopes ER, Pereira MES, Moraes C, Krettli AU, Brener Z. Anticorpos liticos detectados em liquido pericárdico de chagásicos crônicos. Revista da Sociedade Brasileira de Medicina Tropical 17: 127-131, Jul-Set, 1984

certa percentagem de pacientes chagásicos tratados 5 nos quais a sorologia convencional é positiva mas a LMCo é persistentemente negativa.

Considerando ser o AL um marcador bastante confiável de infecção ativa pelo $T$. cruzi, procuramos determinar sua presença no liquido pericárdico de pacientes chagásicos com diferentes tipos de óbito. Nossos resultados demonstram que em todos os 11 chagásicos estudados a pesquisa de $\mathrm{AL}$ foi positiva. Por outro lado nos 12 casos de não-chagásicos a LMCo foi negativa. Esses dados confirmam achados anteriores, observados in vivo, com relação à presença de AL em chagásicos crônicos e à especificidade do método 4,5 , bem como abrem novas perspectivas para o estudo e melhor conhecimento da patologia da tripanossomiase cruzi. É fato bem conhecido que a parasitose tecidual na forma crônica da doença de Chagas é escassa. Mesmo nos órgãos em que parece haver maior parasitismo como no coração ${ }^{2}$ e nas adrenais $^{1}$ a pesquisa direta de parasitas, extremamente trabalhosa, com muita freqüência é negativa. A positividade da LMCo no líquido pericárdico - e eventualmente em outros humores orgânicos - de chagásicos necropsiados poderá portanto se constituir em forte evidência da presença de infecção chagásica ativa mesmo não se encontrando parasitas nos cortes histológicos examinados.

Entre os 11 chagásicos examinados, três casos eram de indivíduos falecidos de modo violento, tendo sido em vida assintomáticos. Neles, os achados morfológicos cardiacos foram semelhantes aos observados nos tripanossomóticos falecidos na chamada forma indeterminada da doença ${ }^{7}$. Ainda que a casuística seja pequena e exija para conclusões definitivas um estudo de maior número de casos, o dado sugere que na forma indeterminada da endemia, a infecção, pelo menos nestes casos, estava em atividade. A presença de AL e de focos flogisticos com exsudato celular conferem substrato a nossa afirmativa. De modo similar nos quatro chagásicos com morte súbita - e nos quais a subitaneidade do óbito foi atribuida à tripanossomiase - os achados também sugerem infecção tripanossomótica ativa.

\section{SUMMARY}

Lytic antibodies ( $L A$ ) investigated by complement-mediated lysis (CoML) test were present in 11 pericardial fluids collected from chagasic patients who died suddenly or from causes not related to the disease and were included in a study of the inde- terminate form of Chagas' disease. In all patients diagnostic conventional serology performed with the pericardial fluid was positive and heart lesions were characteristic or strongly suggestive of Chagas' disease myocardiopathy. In 12 pericardial fluids from non-chagasic patients who died from different reasons, the CoML test was negative. The presence of $L A$ in the pericardial fluid is a strong evidence of active $\mathrm{T}$. cruzi infection in the chagasic patients submitted to necropsy and opens perspectives for further studies and better understanding of the pathology of Chagas' disease.

Key words: Chagas' disease. Pericardial fluid. Lytic antibodies. Anti $-T$. cruzi serology.

\section{REFERENNCIAS BIBLIOGRÁFICAS}

1. Almeida HO, Teixeira VPA, Oliveira ACF. Flebite com parasitismo em supra-renais de chagásicos crônicos. Arquivo Brasileiro de Cardiologia 36: 341-344, 1981 .

2. Andrade Z, Ramalho LMO. Miocardite chagásica (estudo morfológico de 38 casos comprovados pelo encontro de parasitas nas reações histológicas). Gazeta Médica da Bahia 66: 55-67, 1966.

3. Bogliolo L. Miocárdio, endocárdio, pericárdio. In: Bogliolo L (ed). Patologia. Guanabara Koogan, Rio de Janeiro, 1981.

4. Krettli AU, Brener Z. Resistance against Trypanosoma cruzi associated to anti-living trypomastigote antibodies. The Journal of Immunology 128: 2009 $2012,1982$.

5. Krettli AU, Cançado JR, Brener Z. Effect of specific chemotherapy on the levels of lytic antibodies in Chagas' disease. Transactions of the Royal Society of Tropical Medicine and Hygiene 76: 334-340, 1982.

6. Krettli AU, Weiss-Carrington $\mathbf{P}$, Nussenzweig RS. Membrane-bound antibodies of bloodstream Trypanosoma cruz $i$ in mice: strain differences in susceptibility to complement-mediated lysis. Clinical and Experimental Immunology 37: 416-423, 1979.

7. Lopes ER, Chapadeiro E, Andrade ZA, Almeida HO, Rocha A. Anatomia patológica dos corações de chagásicos assintomáticos falecidos de modo violento Memórias do Instituto Oswaldo Cruz 76: 189-197, 1981.

8. Lopes ER, Chapadeiro E, Batista SM, Cunha Jr. JG, Rocha A, Miziara L, Ribeiro JU, Patto RJ. Post-mortem diagnosis of chronic Chagas' disease: comparative eva- 
Lopes ER, Pereira MES, Moraes C, Krettli AU, Brener Z. Anticorpos líticos detectados em líquido pericárdico de chagásicos crônicos. Revista da Sociedade Brasileira de Medicina Tropical 17: 127-131, Jul-Set, 1984

luation of three serological tests on pericardial fluid. Transactions of the Royal Society of Tropical Medicine and Hygiene 72: 244-246, 1978.

9. Mignone $\mathrm{C}$. Alguns aspectos da anatomia patológica da cardite chagasica crônica. Tese de Docència. Faculdade de Medicina da Universidade de São Paulo, São Paulo, 1958.

10. Voller A, Bidwell D, Huldt G, Bartlett A. Microplate enzyme-linked immunoabsorbent assay for Chagas' disease. Lancet 1: 426-428, 1975. 